\title{
Preface
}

\section{A decade of Genome Research celebrated}

Ten years ago Genome Research was launched from the popular platform PCR Methods and Applications as a new journal with a shift in focus from techniques-oriented papers to the application of those techniques to relevant biological questions. This broadening of scope to larger scale genome studies in all species came at a time when genomic tools and resources were burgeoning. Genetic maps had been completed for the human and mouse genomes and physical maps of the human chromosomes were under way. The complete genome sequence of Haemophilus influenzae had just been published (1995) and it was clear that the era of genome sequencing was about to unfold. Since then, hundreds of bacterial genomes and model organisms, such as the yeast Saccaromyces cerevisiae (1996), the nematode Caenorhabditis elegans (1998), and the fruitfly Drosophila melanogaster (2000), as well as the human genome (2001, 2004), have been completely sequenced and many more species boast a range of resources that have in turn revealed the innate complexity of genomes and engendered even more intense inquiry.

The impact of these genomic tools and resources is neither species- nor discipline-specific. Molecular understanding of model species has proven to be translatable, with insights gained in each holding promise for unraveling perplexities in all. Studies in other species ameliorate the human condition, if not by ultimately enabling better prevention, diagnoses, and treatment of human diseases, then, for example, economically; or via the improvement of crops that feed the world; per bioremediation; or through the development of effective insecticides to combat infectious parasites. Furthermore, the usefulness of genomic technology is significant and far-reaching, fueling an increasing number of studies using genomic tools and data in other fields and building bridges most notably to evolutionary biology and genetics.

Today, as we celebrate Genome Research's Ten Year Anniversary, we take stock and reflect upon what we have learned. In these pages you will find Perspectives on a selection of model species-from microbes to human-that strive collectively to il-

'Lindblad-Toh, K., Wade, C.M., Mikkelsen, T.S., Karlsson, E.K., Jaffe, D.B., Kamall, M., Clamp, M., Chang, J.L., Kulbokas III, E.J., Zody, M.C., et al. 2005. Genome sequence, comparative analysis and haplotype structure of the domestic dog. Nature (in press).

Article and publication are at http://www.genome.org/cgi/doi/10.1101/ gr.4923905 lustrate how genomic resources have made a difference. What biological questions were posed with the advent of large-scale genomic resources, how were they elucidated, and what remains enigmatic?

These Perspectives serve as a reminder of the historical intent behind the movements to create such genomic resources and pay homage to the inspired minds fundamental to undertaking such endeavors. Most importantly, they speak to the future of genomic research. There is still promise in the sequence and in other genomic data that is yet to be fulfilled. As we look forward to further insights gleaned from increasingly sophisticated mapping resources, newly sequenced genomes, multispecies genome comparisons, the identification of quantitative trait loci, and the construction of functional and regulatory networks, for example, we acknowledge the achievements along the path that led us here.

Beyond these Perspectives, you will find updates on emerging technologies in DNA sequencing and in gene prediction. Additionally, what better way to attest to the accomplishments of the past decade and to celebrate where we find ourselves at present than with the publication of six dog genome-related papers concordant with today's publication of a high-quality draft sequence of the dog genome (Lindblad-Toh et al. 2005¹)? Among these are novel approaches, analyses, and resources, which not only aid in the interrogation of the canid genome and highlight the uniqueness of canine genetics, but which shed light upon the evolution of a mammalian genome.

Genome Research emerged in 1995 with the goal of publishing the best and most creative research in the field of genomics. At that time, the editors recognized that, in the future, the fruits of the genome projects (those in progress and those that would come) would be the tools that would allow us to "probe biology in an unprecedented manner" and declared that Genome Research would be about that future. We have endeavored to serve the needs of the community by publishing the ripest fruits of your labor-the novel technologies, data, and analyses that conceptually advance our understanding of genome structure and function and address biological conundrums, such as the genotypephenotype connection, which motivate us all. Now, a step forward in time and well on our way, we are still about that future.

Hillary E. Sussman, for the Editors of Genome Research 


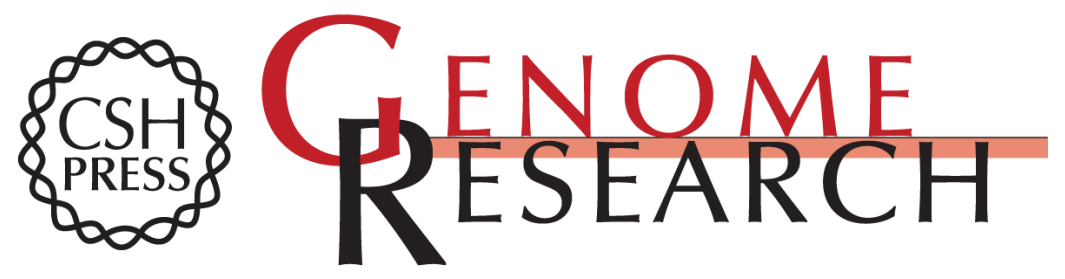

\section{A decade of Genome Research celebrated}

Hillary E. Sussman

Genome Res. 2005 15: xi

Access the most recent version at doi:10.1101/gr.4923905

\section{License}

Email Alerting Receive free email alerts when new articles cite this article - sign up in the box at the Service top right corner of the article or click here.

\section{Affordable, Accurate Sequencing.}

To subscribe to Genome Research go to: https://genome.cshlp.org/subscriptions 